\title{
Trading Power Savings for Blocking Probability in Dynamically Provisioned WDM Networks
}

\author{
Paolo Monti, Member, IEEE, Pawel Wiatr, Amonrat Jirattigalachote, Lena Wosinska, Member, IEEE \\ The Royal Institute of Technology KTH/ICT, Electrum 229, 16440 Kista, SWEDEN \\ Tel: (46) 8790 4076,Fax: (46) 8790 4090,e-mail:pmonti@kth.se
}

\section{EXTENDED ABSTRACT}

In those networking scenarios (e.g., the stationary/mobile wireless paradigm) where limited energy storage capabilities is a limiting factor, power efficiency has been studied extensively for a long time. In the last few years, the steadily growing power consumption figures of ICT [1][2] along with a recent public awareness of the possible environmental effects, broadened the focus of the research efforts towards more power conscious solutions also for wired networks. One promising solution going in this direction is represented by transparent wavelength division multiplexing (WDM) networks, where all-optical circuits (or lightpaths) carry the network traffic from the source to the destination node in the optical domain, i.e. without any optical-to-electrical (O-E-O) conversion. To further improve network power efficiency, several approaches have been proposed in the literature attempting to reduce the power consumption in transparent WDM networks [3][4]. Among them, power aware (PA) routing and wavelength assignment (RWA) algorithms are receiving a lot of attention. One possible solution for the PA-RWA problem is to limit the number of devices in the network that need to be powered-on to support the lightpath requests [5]. These methods, however, have an adverse impact on the length of the provisioned lightpaths. In order to efficiently use as much powered-on network resources as possible, the path length is, on average, longer than the one found with traditional (and less power efficient) shortest path solutions. This is in contradiction with the goal of classical RWA algorithms that tend to minimize the resource usage (i.e., wavelengths and fibers) within the network, in order to minimize the blocking probability. When availability of network resources becomes something that cannot be overlooked, a trade off needs to be assessed between power savings and blocking probability.

In this talk, a non-conventional solution to the PA-RWA problem is presented. It is based on the intuition that, in some cases, relaxing the power minimization constraint can have beneficial effects on the overall network performance, i.e., it can contribute to the reduction of resource fragmentation in the network and, in this way, lower the blocking probability. The proposed algorithm leverages on a cost function that considers both the power status of network elements (in this particular case the in-line optical amplifiers on fiber links only) and the information about wavelength usage. The algorithm has been tested using a Pan-European core network (i.e., COST 239). Performance results confirm the presence of a trade-off between energy saving and blocking probability. They also suggest that a "binary" approach using only the powered-on/powered-off information might not always be the best choice.

Keywords: Green networks, power-aware routing, routing and wavelength assignment (RWA), power efficiency, dynamic lightpath provisioning, blocking probability.

\section{ACKNOWLEDGEMENTS}

The work described in this paper was carried out with the support of the BONE-project ("Building the Future Optical Network in Europe"), a Network of Excellence funded by the European Commission through the 7th ICT-Framework Programme.

\section{REFERENCES}

[1] “An inefficient truth”, Global Action Plan Report, http://www.globalactionplan.org.uk/, Dec. 2007.

[2] “Where Does Power Go?”, http://www.greendataproject.org/, Jan. 2008.

[3] E. Yetginer, and G. N. Rouskas, "Power efficient traffic grooming in optical WDM networks", in Proc. of IEEE GLOBECOM 2009, Nov.-Dec. 2009.

[4] G. Shen and R. Tucker, "Energy-Minimized Design for IP Over WDM Networks", J. of Opt. Comm. and Netw., vol. 1, no. 1, June 2009.

[5] Y. Wu, L. Chiaraviglio, M. Mellia and F. Neri, "Power-aware routing and wavelength assignment in optical networks", in Proc. of ECOC 2009, Vienna, Austria. 